\title{
RECONFIGURAÇÕES DIDÁTICO-PEDAGÓGICAS NA EDUCAÇÃO DE JOVENS E ADULTOS TRABALHADORES: REFLEXÕES A PARTIR DAS RELAÇÕES RACIAIS E DO ENSINO DE GEOGRAFIA
}

\section{TEACHING-PEDAGOGICAL RECONFIGURATIONS IN THE EDUCATION OF YOUNG AND ADULT WORKERS: REFLECTIONS FROM RACIAL RELATIONSHIPS AND TEACHING GEOGRAPHY}

\author{
Tiago Dionísio da Silva \\ Universidade Federal Rural do Rio de Janeiro
}

\begin{abstract}
RESUMO
O racismo é um problema estrutural e seu combate passa, obrigatoriamente, e também, pela intervenção educativa. Daí a importância de refletirmos como o tema é tratado no sistema escolar, uma vez que acreditamos que este seja capaz de contribuir para a transformação do imaginário, dos valores, das culturas e das condutas. Neste sentido, este artigo apresenta uma análise do material didático de Geografia do Programa "Nova EJA" com recorte para as relações raciais, mais especificamente como se dá a representatividade da população negra no referido material, uma vez que o segmento negro da sociedade brasileira é a maioria nos bancos escolares na EJA. A partir das análises sobre as imagens e conteúdosdos cadernos dos estudantes, chegamos aos seguintes resultados: o material ofertado pelo Programa "Nova EJA", que se propõe inovador com vista a combater a defasagem entre idade/série e evasão escolar, precisa trazer em seu cerne uma nova concepção educacional em que a população negra se veja representada positivamente e, assim, incluída no sistema escolar, visto que a representação da população negra está negligenciada, estigmatiza e estereotipada, reforçando, assim, o racismo institucional no espaço escolar e colaborando para práticas pedagógicas racistas.
\end{abstract}

Palavras-chave: Educação de Jovens e Adultos Trabalhadores; Relações Étnico-raciais; Ensino de Geografia; Programa "Nova EJA"; Material didático.

\section{ABSTRACT}

Racism is a structural problem and its fight must, necessarily, and also, through educational intervention. Hence the importance of reflecting how the theme is treated in the school system, since we 
believe that it is capable of contributing to the transformation of the imaginary, values, cultures and behaviors. In this sense, this article presents an analysis of the didactic material of Geography of the Program "Nova EJA" with cut for the ethnic-racial relations, more specifically as it is the representativeness of the black population in the referred material, since the black segment of the society is the majority in school banks at EJA. From the analysis of the images and contents of the two volumes of the students' notebooks, we arrived at the following results: the material offered by the Nova EJA Program, which is innovative in order to combat the gap between age / grade and school dropout, needs to bring at its core, a new educational concept in which the black population is positively represented and thus included in the school system, since the representation of the black population is neglected, stigmatized and stereotyped, thus reinforcing institutional racism in the school space and collaborating for racist pedagogical practices.

Keywords: Education of Youth and Adult Workers; Ethnic-racial relations; Geography teaching; "Nova EJA" program; Courseware. 


\section{INTRODUÇÃO}

A Nova Política para a Educação de Jovens e Adultos ("Nova EJA"), implantada no estado do Rio de Janeiro, em 2013, sob a responsabilidade pedagógica do Centro de Ciências e Educação Superior a Distância do Estado do Rio de Janeiro (Fundação CECIERJ), impôs uma reestruturação curricular. Houve diminuição dos tempos diários de aula de 6 para 4, oferta de material didático específico para os professores e estudantes e formação continuada para os docentes com bolsa - esta destinada a custear as despesas como deslocamento e alimentação. ${ }^{1}$

Nicodemos e Flor (2019, p. 145) informam que a referida Política passou a vigorar através da Resolução no $49515^{2}$ que intitulou a "implantação das diretrizes curriculares para a educação básica nas unidades escolares da rede pública e dá outras providências”. Nesse documento está descrito a proposta curricular do programa e ressalta detalhadamente a carga horária das disciplinas que serão ofertadas aos jovens e adultos.

A reestruturação da Educação de Jovens e Adultos (EJA) no estado fluminense aconteceu no bojo da mudança gerencial pela qual o Estado brasileiro vem passando na última década (ANDRADE, 2014; VENTURA, 2016), pois os resultados das avaliações - internas e externas à unidade escolar - e o índice de fluxo escolar foram baixos no ano de 2009, principalmente no Ensino Médio (EM). Assim, a Secretaria de Estado de Educação do Rio de Janeiro (SEEDUC/RJ) aprofundou suas ações através de programas diferenciados para obtenção de melhores resultados, como o "Nova EJA" voltado principalmente para o Ensino Médio.

Neste este artigo apresento uma análise do material didático de Geografia produzido pela Fundação CECIERJ para a Educação de Jovens e Adultos na Rede

\footnotetext{
1 Nova Política para Educação de Jovens e Adultos no estado do Rio de Janeiro ficou conhecida, popularmente, por Programa Nova EJA ou NEJA. A partir de 2016, o programa foi alterado em seu formato de oferta, passando da nomenclatura de NEJA para EJA. Essa alteração não implicou em mudanças significativas na estrutura/concepção na oferta pela SEEDUC/RJ até os dias atuais e nem no Material Didático, concebido e distribuído pela Secretaria de Educação a docentes e discentes (NICODEMOS e FLOR, 2019, p. 139).
}

2 Resolução SEEDUC nº 4951 de 04 de outubro de 2013 com base no processo no 03/o01/5612/13. 
Pública Estadual do Rio de Janeiro, com recorte para as relações raciais, mais especificamente como se dá a representatividade da população negra no referido material, uma vez que o segmento negro da sociedade brasileira é a maioria nos bancos escolares na EJA. Somado a isso, Miguel Gonzalez Arroyo (2007) denuncia que o sistema educacional brasileiro segue ações hierarquizadas e racializadas que implicam na exclusão de grande parte da população brasileira, neste caso, a negra; quando não, essa população está presente, porém invisibilizada política e didaticamente nas práticas pedagógicas e nos materiais didáticos. Logo, analisar o material ofertado pelo Programa "Nova EJA", que se propõe inovador com vista a combater a defasagem idade/série e evasão escolar, precisa trazer em seu cerne uma nova concepção educacional em que a população negra se veja representada positivamente e, assim, incluída no sistema escolar.

Por material didático, aqui, entendo os livros didáticos de Geografia dos estudantes. Michael Apple (1995, p.81) afirma que "os livros didáticos estabelecem grande parte das condições materiais para o ensino e a aprendizagem nas salas de aula de muitos países no mundo [...]. São os textos destes livros que frequentemente definem qual é a cultura legítima a ser transmitida.” Então, vale indagar que cultura esses livros estão transmitindo? Que representação da população negra está posta? Uma vez que ela é o segmento populacional de maior presença nos bancos escolares da EJA.

Vale ressaltar que a história da população brasileira é marcada pelo racismo e pelo mito da democracia racial (HASENBALG, 2005; GOMES, 2005). Isso perpassa o sistema educacional e desemboca no cotidiano do espaço escolar de inúmeras maneiras: práticas pedagógicas racistas, invisibilidade do negro na história brasileira, reforço de estigmas e estereótipos dos estudantes negros. Tais práticas contribuem para o que denominamos apartheid escolar, ou seja, a população negra está na escola, mas de maneira subalternizada e segregada.

Uma das principais ações dos movimentos negros no Brasil é atuar no sistema educacional para combater práticas racistas escolares. Essas práticas são, ao mesmo tempo, explícitas através de dados, mas muitas vezes camufladas por ações que se 
dizem inovadoras, mas que reforçam o racismo, como por exemplo o material didático do Programa "Nova EJA".

Divido este artigo em três partes: na primeira discuto a origem e a proposta político-pedagógica do Programa "Nova EJA"; na segunda apresento uma discussão teórica sobre a necessidade de reconfiguração da política pública da EJA e da Geografia Escolar que contemple os "novos sujeitos"; e na última parte analiso a representação da população negra no material didático de Geografia do Programa.

\section{POLÍTICA DE FORMAÇÃO PARA EDUCAÇÃO DE JOVENS E ADULTOS TRABALHADORES NO ESTADO DO RIO DE JANEIRO: CONSIDERAÇÕES A PARTIR DO PROGRAMA “NOVA EJA"}

O Programa "Nova EJA" é fruto de um novo modelo de gestão que se pressupõe inovador e começou a ser implantado na Rede Estadual Pública de Ensino do Rio de Janeiro em 2009, após o referido Estado ter amargado a penúltima colocação no ranking do Índice do Desenvolvimento da Educação Básica (IDEB).

O programa em análise resulta do conjunto de reformas realizadas pela SEEDUC-RJ após o ano de 2009, em consequência imediata da penúltima colocação no ranking do (IDEB). O mesmo insere-se no denominado "choque de gestão", como classificado pelo então Secretário de Educação do Estado do Rio de Janeiro, Wilson Risolia, em entrevista ao jornal O Globo no dia 14 de agosto de 2012. Tal termo especifica-se, pela ótica do secretário, em melhorar a qualidade da educação do estado em comparação às demais unidades federativas, o que salienta a prerrogativa performática como primeira hipótese, vide o ranqueamento como indicativo qualitativo (ANDRADE, 2014, p.37).

Nesse sentido, foram traçadas estratégias e planos objetivando a melhoria na posição no IDEB. A pretensão do então Secretário Estadual de Educação, Wilson Risolia, era colocar o Rio de Janeiro entre as cinco melhores Redes Públicas do ranking do IDEB. 3 Jaqueline Pereira Ventura assim se refere a esse processo:

\footnotetext{
3 De fato, isso ocorreu, pois o EM no estado fluminense saiu da $26^{\circ}$ posição em 2009 para a $4^{\circ}$ posição em 2013.
} 
Sob o argumento de que melhoraria a qualidade da educação do RJ e promoveria melhores resultados do desempenho escolar, a SEEDUC/RJ elaborou, em 2010, o planejamento estratégico para orientar a política estadual de educação. Esse modelo gerencial adotado definiu o modo de organização, o financiamento e a gestão das unidades escolares, pautando-se, principalmente, na Gestão Integrada na Escola (GIDE) e no Programa de Bonificação por Resultados. A meta era tornar o estado do Rio de Janeiro uma referência nacional de qualidade e eficiência na educação pública, com o objetivo imediato de elevar a posição da rede estadual no ranking do Índice de Desenvolvimento da Educação Básica (IDEB). (VENTURA, 2016, p.17).

Nesse processo, destacam-se algumas questões relacionadas ao baixo rendimento dos estudantes, a saber: falta de instrumento diagnóstico; falta de alinhamento ao currículo; aulas com baixa atratividade; alunos com dificuldade de aprendizagem; e a elevada distorção idade-série. Compreende-se a partir da argumentação da SEEDUC que o problema central da baixa qualidade da educação se relaciona com a ineficiência da gestão, pelo fato de não ser técnica, daí a justificativa para o "choque de gestão" e a implantação da Gestão Integrada da Escola (GIDE).

O "Nova EJA" nasce com o objetivo de sanar as inúmeras tentativas frustradas de políticas públicas voltadas para a EJA, de tornar a referida modalidade de ensino pedagogicamente mais dinâmica e atraente - combatendo a evasão, a defasagem idade/série, e de potencializar o direito à educação para os sujeitos historicamente excluídos do sistema escolar. A estrutura organizacional do "Nova EJA" é baseada em duas instâncias estaduais: a SEEDUC e a Secretaria de Estado de Ciência e Tecnologia (SECT4). A SEEDUC ficou responsável pelos recursos humanos e pela infraestrutura física, ou seja, os docentes concursados ou contratados, as unidades escolares e a gestão dos discentes. Coube à SECT, por meio da Fundação CECIERJ, a organização curricular do referido Programa.

Construído sob uma concepção de tecnologia educacional que objetivou reformular toda a estrutura curricular da EJA no Rio de Janeiro. Essa reestruturação, segundo o Manual de Orientação do Programa "Nova EJA", foi baseada em quatro pilares: 1) Material didático específico para o aluno; 2) Metodologia específica; 3) Roteirização de aula para o professor; 4) Formação continuada. Segundo a concepção

4 Atualmente denomina-se Secretaria de Estado de Ciência, Tecnologia e Inovação (SECTI). 
proposta está explícita a reprodução unilateral dos recursos disponíveis pela Secretaria mencionada, uma vez que a restruturação passa somente pelo viés educacional com o objetivo de alcançar uma maior quantidade de certificação, desconsiderando o contexto socioeconômico em que os estudantes estão inseridos que os impedem concluírem a Educação Básica.

Nicodemos e Flor (2019, p.144) consideram que [...]:

a Nova Política de Educação de Jovens e Adultos (NEJA) se configura numa dimensão formativa de unilateralidade dos sujeitos e foi elaborada como uma política de escolarização como expressão de uma dualidade educacional de novo tipo. Nessa perspectiva, Rummert, Algebaile e Ventura (2013) indicam: "Na atual forma histórica de dualidade educacional, o elemento novo é constituído pelas ofertas educativas que propiciam possibilidades de acesso a diferentes níveis de certificação, falsamente apresentados como portadores de qualidade social igual a das certificações às quais têm acesso a burguesia” (p. 273).

Outra inovação que o Programa trouxe foi explicitar o direito dos estudantes de 18 anos ou mais poderem se matricular na EJA EM, conforme está indicado no Art. $6^{\circ}$, observado no disposto do artigo $4^{\circ}$, inciso VII, da Lei $n^{0}$ 9.394/96 - a idade mínima para matrícula em cursos de EJA de Ensino Médio, inscrição e realização de exames de conclusão de EJA do EM é 18 anos completos. Somado a isso, tornou obrigatória a matrícula dos estudantes com idade acima de 21 anos, através do sistema informatizado "Matricula Fácil”, impedindo que estudantes com essa idade optem pelo EM Regular, na hora da realização da inscrição no sistema.

Além disso, ao alocar automaticamente os estudantes com mais de 21 anos nas turmas da EJA, acarretando, assim, uma triagem dos estudantes, o que gera uma segregação dentro do próprio sistema educacional, uma vez que impede os estudantes elegerem a modalidade educacional que desejam cursar. Além disso, também é uma forma de homogeneizar as turmas do EM regular.

O programa Nova EJA pode ser enquadrado, assim, como modelo de política pública que visa, através de novas propostas curriculares elevar a escolarização e a certificação de jovens e adultos trabalhadores, buscando, sem grandes investimentos, impactar positivamente os dados estatísticos em relação ao nível de escolaridade da população mais pobre, bem como, apresentar para a população uma iniciativa original por parte do governo em 
relação ao cumprimento do direito à educação. (NICODEMOS e FLOR, 2019, p. 144).

Analisar o "Nova EJA” possibilita compreender alterações na matriz curricular, diminuição dos tempos de aula, extensão do plano de curso de um ano e meio para dois anos e alternância da oferta dos componentes curriculares em disciplinas, com ênfase em Ciências Humanas e da Natureza, fragmentando ainda mais o currículo escolar. De acordo com a matriz curricular do programa,

Cada Módulo terá duração correspondente a 01 (um) semestre letivo, totalizando, para efeito de conclusão do Ensino Médio, em 4 (quatro) semestres letivos ou 2 (dois) anos. A carga horária diária de aulas, compreendida em turnos de 4 horas, será de 4 tempos de 50 minutos de aulas das disciplinas obrigatórias e 50 minutos para disciplinas optativas e dependência. No mesmo turno serão oferecidas aulas de Ensino Religioso (1 x semana), Língua Estrangeira optativa (1 x semana) e dependência. Estas aulas, de 50 minutos, acontecem antes de iniciar o turno de aulas da EJA Ensino Médio, ou ao final entre um turno e outro. (RIO DE JANEIRO, 2013a, p.8).

Segundo o Manual de Orientações, o curso está dividido em quatro módulos, divergindo da estrutura de anos e séries semestrais que vigoravam. Cada módulo tem duração correspondente a um semestre letivo, totalizando, para efeito de conclusão do EM, quatro semestres, ou dois anos. A carga horária diária de aulas é de quatro tempos de 50 minutos cada, para as disciplinas obrigatórias e optativas. Ao longo dos quatros módulos, apenas as disciplinas de Língua Portuguesa, Matemática e Ensino Religioso são constantes. As demais ocorrem divididas entre os módulos.

Outra situação complexa é a questão da carga horária. Sob a justificativa de otimizar o tempo e viabilizar a permanência dos estudantes na escola, para a SEEDUC não fazia mais sentido ter seis tempos diários como era na "EJA Terminal", pois o primeiro tempo era desperdiçado, visto que os estudantes não o frequentavam. Minha hipótese para essa situação de ociosidade do primeiro tempo de aula (18h15min) se dá em função da mobilidade urbana, da questão do trabalho, entre outros fatores. Além disso, por causa do cansaço da jornada de trabalho e dos problemas de violência urbana na Região Metropolitana, os discentes também não permaneciam até o último tempo de aula (22h25min).

Como demonstra Ventura: 


\begin{abstract}
Essa concepção de EJA pautada em aceleração e correção do fluxo escolar é claramente expressa no Relatório de Gestão e Políticas Públicas de 2014, onde, segundo um organograma denominado Árvore de Soluções, para o problema de 'queda da distorção idade-série' a solução é 'Autonomia e Nova EJA' (SEEDUC, 2014, p.11). Em outras palavras, a EJA, no nível médio, no Rio de Janeiro, mesmo que sob nova roupagem, continua sendo tratada pelo governo estadual, principal responsável por sua oferta, com uma concepção de suplência, de compensação e de correção de fluxo escolar. (VENTURA, 2016, p.20).
\end{abstract}

Na verdade, esses são problemas da educação brasileira como um todo, porém, quando analisados na EJA, tornam-se mais intensos e grandiosos, uma vez que esbarramos com as trajetórias escolares que já foram descontínuas por conta das mazelas do sistema capitalista, que impõe o abandono precoce da escola por muitos brasileiros, devido ao ingresso no mundo do trabalho, em prol da sua própria sobrevivência. Além disso, há a forte presença de estruturas escolares arcaicas que reforçam o racismo estrutural, o que não gera uma identificação dos estudantes com o ambiente escolar, provocando evasão e desinteresse pela escolarização.

\title{
ENSINO DE GEOGRAFIA E “NOVOS SUJEITOS”: RECONFIGURAÇÕES POLÍTICAS E QUEBRA DE PARADIGMAS
}

A Lei 10.639 - sancionada em 2003 pelo Presidente da República Luiz Inácio Lula da Silva -, que alterou a LDB de 1996 e instituiu a obrigatoriedade no EF e EM público e privado, do ensino de História e Cultura Africana e Afro-Brasileira, é fruto da luta dos movimentos negros. Tal luta se intensificou principalmente no século passado, com vistas a garantir a cultura africana e afro-brasileira nos currículos escolares com o fim de construir uma identidade entre os estudantes e o ambiente escolar. Sobre esse processo, Renato Emerson dos Santos destaca:

Em janeiro de 2003, foi promulgada a Lei 10639/03. Fruto de lutas históricas do movimento Negro brasileiro, as indicações contempladas pela Lei já apareciam no Congresso Nacional do Negro Brasileiro na década de 1950 cujo documento final continha entre recomendações 'estimulo ao estudo das reminiscências africanas no país, bem como a remoção das dificuldades dos brasileiros de cor [...], e, posteriormente, nos anos de 1980, foi apresentada 
como Projeto de Lei na Constituinte de 1988 e sua aprovação reivindicada na Marcha Zumbi em 1995'. Sua aprovação visa alterar a Lei de Diretrizes e Bases da Educação, assumindo o papel do mundo da educação como fundamental na reprodução e na reversão do quadro de desigualdades raciais no Brasil. (SANTOS, 2007, p.22).

Ainda que a Lei tenha determinado as áreas de Educação Artística, Literatura e História como componentes curriculares "carros-chefe" para a implantação dos seus objetivos, o que se propõe é a extensão para as demais áreas do currículo escolar, como a Geografia, por exemplo; e que esses objetivos sejam discutidos em todas as modalidades de ensino. Partindo dessa perspectiva, Nilma Lino Gomes (2011) chama atenção para o lugar do debate sobre a questão racial nas diversas modalidades de ensino, em especial na EJA:

Nesse contexto, os níveis e as modalidades de ensino que antes contemplavam minimamente ou desconsideravam o impacto da dimensão étnico-racial na formação da nossa sociedade, nos destinos e trajetórias sociais e escolares dos negros e das negras são chamados para o debate. E a grande questão é: qual é o lugar ocupado pela questão racial na EJA? (GOMES, 2011, p.90).

Debater a questão racial na EJA a partir da Geografia é relevante, pois a referida ciência busca enfrentar a posição e o reposicionamento dos indivíduos no mundo a partir do seu lugar, do seu território, do seu espaço geográfico mediados pelas configurações e reconfigurações construídas a partir de relações complexas e estruturadas pelas questões sociais, culturais, econômicas e raciais.

A vida do estudante da EJA é atravessada por inúmeras questões sociais, culturais, econômicas e raciais. Assim, a raça, como elemento que regula as relações sociais no Brasil, de alguma forma tem suas manifestações e tensões grafadas no espaço geográfico brasileiro. Com isso, queremos dizer que os jovens e adultos e, por consequência, a população negra, não ocupam qualquer território desse espaço. Esses sujeitos são estrategicamente empurrados para as favelas e periferias, onde a presença dos aparelhos estatais é precária, bens culturais escassos, transportes públicos deficitários. Essas análises são inerentes à Geografia e, portanto, ao ensino dela. Por isso, seu ensino deve atentar para o fato de que emergem as desigualdades socioeconômicas e raciais materializadas no espaço. "Dessa forma, construir um 
conhecimento que leve os jovens e adultos trabalhadores brasileiros compreender o contexto social em que estão inseridos.” (NICODEMOS e FLOR, 2019, p. 144).

[...] a reflexão sobre a geografia a ser ensinada na Educação de Jovens e Adultos (EJA), modalidade da educação básica que se diferencia da educação escolar de crianças e adolescentes pelo conjunto de características específicas de seu público, em geral detentor de experiências significativas de vida e possuidor de intensa inserção no mundo do trabalho. Junto a estes traços que são próprios da condição de não crianças, os alunos da EJA, principalmente os que frequentam o sistema público de ensino, trazem também a marca da sociedade de classes. Jovens, adultos e idosos cursam esta modalidade de ensino porque, invariavelmente, a inclusão prematura no mundo do trabalho é, na maioria das vezes, um imperativo, uma exigência em função das condições socioeconômicas nas quais se encontravam na infância e/ou na adolescência (SERRA, 2011, p.25).

Trazer a Geografia para o centro do debate sobre raça e racismo, como elementos estruturantes da sociedade brasileira, impõe um desafio ao pensar o seu próprio ensino, considerando essas temáticas complexas e até então pouco exploradas. A Geografia e, por extensão, o seu ensino - ao problematizar, refletir e construir novas análises, tendo como ponto de partida, também, a questão racial - constroem-se deixando de ser uma mera disciplina de caráter enciclopédico e europeizado, passando a ser uma forma, também, de desvendar o racismo e seus impactos sociais, além de contribuir para construção de visões de mundo comprometidas com a igualdade social. Santos reforça que:

\footnotetext{
Uma reflexão acerca da inserção da temática racial no ensino de Geografia torna forçoso, portanto, uma reflexão acerca do(s) sentido(s) de aprender/ensinar Geografia, pois é o sentido, enquanto manifestação de visões de mundo e de projetos societários, que orienta a práxis, é ele que vai definir a forma como tal temática é (ou não) abordada. (SANTOS, 2007, p.2526).
}

Sendo a Geografia a ciência que estuda o espaço construído pelos seres humanos, é preciso considerar que esses seres humanos têm uma raça e que essa condição racial - por meio do racismo - foi um elemento fundamental para que impusessem a ele um lugar espacial e social. Recorrendo novamente a Santos (2007): 
falamos isso, estamos indicando na verdade uma dupla acepção do que chamamos 'se posicionar no mundo': (i) conhecer sua posição no mundo, e para isto o indivíduo precisa conhecer o mundo; (ii) tomar posição neste mundo, que significa se colocar politicamente no processo de construção e reconstrução deste mundo. Se posicionar no mundo é, portanto, conhecer a sua posição no mundo e tomar posição neste mundo, agir. Saber Geografia é saber onde você está, conhecer o mundo, mas isto serve fundamentalmente para você agir sobre este mundo no processo de reconstrução da sociedade: se apresentar para participar. (SANTOS, 2007, p.27, grifos do autor).

Partindo desses pressupostos, vale compreender que, "as ciências vêm sendo desafiadas diante de fenômenos e processos de grandes envergaduras que o mundo vem experimentando, sobretudo nos últimos 40 anos" (PORTO-GONÇALVES, 2007, p.7). Nesse sentido, tal reconfiguração, manifestado nas ciências em geral, e na Geografia em particular, constituída sob a forte a influência eurocêntrica que escravizou os africanos, exterminou os povos indígenas e oprimiu os pobres. Como destaca Carlos Walter Porto-Gonçalves:

\begin{abstract}
Quanto às ciências ditas humanas os desafios não são menores. Para perder o fio com o anterior considere-se o fato de que as ciências humanas não podem mais continuar a ignorar a inscrição material da sociedade na natureza por meio do espaço geográfico. Mas não param por aí os desafios. Grandes fenômenos e processos sociais colocam os paradigmas hegemônicos das ciências sociais em questão como, por exemplo, a queda do muro de Berlim e, sobretudo, a emergência de novos protagonistas reivindicando o 'direito a ter direitos' como mulheres, os povos originários e os afro-latino-americanos. [...] As ciências humanas, inclusive as ciências híbridas como a Geografia, não estavam preparadas para a emergência desses movimentos. Antes de tudo porque continuam prisioneiras do eurocentrismo e não conseguem analisar criticamente o significado da noção de modernidade e, assim, tornam essa noção um fundamentalismo. (PORTO-GONÇALVES, 2007, p.8-9).
\end{abstract}

Esses fenômenos, aos quais o autor se refere como promotores da quebra de paradigma das ciências, têm intrínseca relação à EJA. Desse modo, reconfigurar a EJA como um espaço público, democrático e de direito significa, conectar-se às mudanças que vêm ocorrendo no mundo. São dois lados de uma mesma moeda, pois, assim como as ciências humanas são colocadas em xeque - porque ao olharem para a "história da EJA, essas vivências foram interpretadas politicamente como opressão, como negação da liberdade, como desumanização" (ARROYO, 2011, p.41) -, do mesmo modo implicaram em uma reconstrução, visto que "a educação desses jovens e adultos foi 
assumida como um ato político como exercício de emancipação e libertação" (ARROYO, 2011, p.41).

Assim, é necessário refletirmos sobre uma Geografia que abarque essas novas demandas, levando em conta que a questão racial tem um protagonismo a ser considerado nesse debate, visto que ao longo da história brasileira a população negra ficou à margem dos direitos sociais. Além disso, as análises geográficas não se preocuparam em incorporar as reivindicações da população negra, pois "o sistema mundo moderno-colonial, e sua Geografia, se conformou por meio da discriminação racial” (PORTO-GONÇALVES, 2007, p.11). Dito de outro modo, mas, nas palavras do mesmo, autor:

\begin{abstract}
Não olvidemos que a África que temos hoje não é o resultado da história dos povos africanos somente, mas a história da subordinação, exploração, diáspora que constituiu a formação geográfica daquele continente, sobretudo depois da subordinação imposta pelos europeus por meio de seus conquistadores, religiosos e negociantes. A Geografia, quando liberta do eurocentrismo começa a deixar falar as relações sociais e de poder que conforme o espaço assimétrico do sistema mundo moderno-global. (PORTOGONÇALVES, 2011, p.10).
\end{abstract}

Tal situação não tem reflexo somente no Brasil, mas é uma guinada de concepções, mudanças conceituais e paradigmáticas de escala global, no sentido que tem repercussão na educação a partir de inspirações das lutas reivindicatórias país afora. Porto-Gonçalves (2007) aponta, ainda, a intrínseca relação entre os movimentos negros, a educação e a Geografia e, no mesmo sentido, Mônica Lima (2006) defende a importância do continente africano para a humanidade:

E ainda devemos lembrar que a História da África é parte indissociável da história da humanidade, na sua expressão mais completa. A África é o berço da humanidade, lá surgiram as primeiras formas gregárias de vida dos homens e mulheres no nosso planeta. Em toda sua longa história, os nativos do continente africano estiveram relacionando-se aos habitantes de outras regiões e continentes. Seus conhecimentos, produtos, criações e ideias circularam o mundo, assim como seus criadores. (LIMA, 2006, p.74).

Se dentro da própria Geografia existe uma crise de paradigmas - tanto no âmbito acadêmico como no âmbito escolar -, essa crise não é um privilégio exclusivamente seu. Segundo Arroyo, trata-se também do desdobramento de 
acontecimentos no setor educacional e da pressão social pelo qual o mundo está passando.

\begin{abstract}
Reações semelhantes, encontramos nas escolas: políticas educacionais, de um lado, e nas campanhas como todos pela educação, toda criança na escola, democratização da educação infantil 4-5 anos e universalização (quase) do Ensino Fundamental de novos anos. De outro lado, as reprovações, retenções, defasagens idade-série, a separação das turmas de alunos exitosos, de um lado, e repetentes, defasados, desacelerados, indisciplinados, de outro. As classificações de alunos, de escola privada $v s$ pública, de qualidade $v s$ sem qualidade estão mais fortes com a chegada dos (as) filhas (as) dos trabalhadores empobrecidos, das periferias e dos campos. As formas de pensar essas infâncias e adolescências e de pensar os diferentes se tornaram mais duras, mais negativas na medida em que se fazem mais presentes e afirmativos, lutando por direitos. (ARROYO, 2012, p.122).
\end{abstract}

Todo esse rearranjo impõe novas posturas científicas frente a esses novos sujeitos e suas demandas. Colocando em xeque a produção do conhecimento, os modos de se produzir ciência, e seus desdobramentos com foco na sala de aula. Todavia, de que maneira esses conhecimentos sistematizados têm contribuído para a dissolução dessa crise construída por esses "novos sujeitos"? Como a Pedagogia está lidando com isso? Como a Geografia incluiu essas novas reivindicações? Segundo Arroyo, estamos diante de um cenário complexo e, nesse sentido, o autor questiona:

\begin{abstract}
Por que as presenças dos diferentes se tornam um incomodo e provocam reações de controle? Porque como diferentes propõem outro projeto de campo, de cidade e de sociedade, de escola e de universidade. Porque se contrapõem a apropriação/expropriação da terra e do espaço, a exploração do trabalho e a destruição da agricultura camponeses, da produção de alimentos para a vida. A diversidade de lutas e de ações coletivas populares e de movimentos sociais mexe nas estruturas e relações mais brutais de dominação/subordinação dos trabalhadores, dos setores populares. Trazendo as lutas para o direito à terra, teto, moradia, trabalho, vida, escola, universidade, instalam os direitos nos núcleos estruturantes das relações políticas de dominação/subordinação. Da produção-reprodução das desigualdades. A reação política a esses movimentos expõe a radicalidade política que eles trazem para as relações políticas e econômicas, culturais e pedagógicas. (ARROYO, 2012, p.122).
\end{abstract}

E no bojo dos movimentos sociais reivindicatórios temos as lutas dos movimentos negros pelo reconhecimento das desigualdades raciais no Brasil, até então invisibilizadas pelo mito da democracia racial que impera em nosso país. Assim, os aspectos da população negra não eram levados em conta e muito menos reconhecidos, 
devido à falácia de que todos são iguais, passíveis de se desenvolverem e ascenderem social e economicamente. Sales Augusto Santos alerta que

\begin{abstract}
Embora existam estudos que demonstrem a responsabilidade da escola na perpetuação das desigualdades sociais, como, por exemplo, Bourdieu (1998), não há dúvidas de que para os negros a busca da instrução (educação formal) como fator de integração socioeconômica e competição com os brancos, logo após a abolição da escravatura, foi um passo correto; porém, não suficiente para a sua ascensão social. Os negros compreenderam que sem educação formal dificilmente poderiam ascender socialmente, ou seja, obter mobilidade vertical individualmente ou coletivamente, numa sociedade em pleno processo de modernização. (SANTOS, 2005, p.22).
\end{abstract}

Nessa perspectiva, a escola passa a ter um enorme valor para os negros, pois eles enxergaram na educação formal uma estratégia para ascenderem socialmente. Então, a partir daí, o espaço escolar vem recebendo "novos sujeitos", antes à margem desse mesmo espaço. Porém, o fato de eles estarem presentes, ao longo do tempo, não significou que eram compreendidos como parte de uma sociedade. Simplesmente o sistema escolar os absorveu, mas não garantiu que suas especificidades socioeconômicas, políticas e culturais fossem incorporadas ao universo escolar. Assim, “[...] a escola ou a educação formal não foi e nem é a panaceia para os negros brasileiros. Logo a militância e os intelectuais negros descobriram que a escola também tem responsabilidade na perpetuação das desigualdades raciais" (SANTOS, 2005, p.22).

Germán Wettstein (2005) nos convida a refletir sobre que geografia ensinar, considerando “[...] o mundo tal qual ele é (e não tal qual ele foi)” (WETTSTEIN, 2005, p.126), pois esses "novos sujeitos" reconfiguraram o mundo como o conhecemos, revelando algo que é negligenciado. Isso implica em uma nova educação, uma nova escola, dotada de prática pedagógica reconfigurada, por consequência, em um novo olhar geográfico que contemple a questão racial.

Já não é mais possível educar como educávamos. As disputas no campo político do mundo exterior batem à porta da escola e obrigam essa instituição a se reconfigurar e com ela toda sua cultura, pois a escola abriga pobres, negros, quilombolas, mulheres, homossexuais, indígenas, trabalhadores urbanos, rurais, uma gama de religiões, saberes, vivencias e experiências, como o demonstra Arroyo: 
No momento em que os setores populares repolitizam o papel dessas representações inferiorizadas ao longo da história da sua segregação, subordinação e negação de seus direitos, o campo das representações sociais passa a ser um dos campos de disputa política, mas também pedagógica. As formas de pensar os educandos condicionam as formas de educá-los. Condicionam o pensamento pedagógico. As teorias pedagógicas não ficam à margem dessas tensões, nem as políticas, os currículos, nem a cultura escolar e docente. São pressionadas a repensar as representações dos educandos e dos coletivos populares com que trabalham nas escolas, na EJA, na educação popular. As lógicas estruturantes do sistema escolar são pressionadas a se repensar. A cultura política tão segregadora é obrigada a se repensar. (ARROYO, 2012, p.125).

Na visão de Wettstein (2005), a Geografia precisa dar conta de conteúdos tradicionais, mas também se preocupar não mais como o mundo era, mas sim como o mundo está hoje. Além disso, como o mundo mudou, o espaço geográfico mudou também e, consequentemente, os sujeitos produtores desse espaço geográfico não ficaram isentos a essa mudança.

Contribuindo para o debate, Nídia Nacib Pontuschka, Tomoko Iyda Paganelli e Núria Hamglei Cacete destacam:

A Geografia, como ciência, avançou em seus vários ramos, e deveria ter havido uma contribuição maior para seu ensino e aprendizagem. No entanto, é preciso lembrar que o movimento e o ritmo de mudanças nas sociedades se alteraram, as relações internacionais se mundializaram e se globalizaram, o neoliberalismo se expandiu e vem, de forma profunda, interferindo no cotidiano de nossas vidas e também no cotidiano escolar. Na atualidade, tais transformações exigem urgentemente a criação de respostas como novos conteúdos. Os conteúdos convencionais intrínsecos à Geografia precisam ser vistos por novos prismas. (PONTUSCHKA et al., 2007, p.25-26).

\section{Assim, a Geografia precisa reconfigurar suas bases didático-pedagógicas no} sentido de atender esses "novos sujeitos". Pontuschka aponta a necessidade de ter como ponto de partida a condição de existência desses alunos, pois

As condições de existência dos próprios alunos e seus familiares são ponto de partida e de sustentação que podem garantir a compreensão do espaço geográfico, dentro de um processo que vai do particular ao geral e retorna enriquecido ao particular. Enfim, propiciar aos alunos a vivência de um método de trabalho que possa ser usado em diferentes situações, para que eles, gradativamente, adquiram autonomia no processo de produção do conhecimento, é um aspecto importante que o educador deve buscar. (PONTUSCHKA, 2005, p.133). 
Nesse sentido, mais uma vez reitero a importância da Geografia na discussão da questão racial, pois “as relações raciais grafam o espaço, se constituem no espaço e com o espaço. Revelar estas espacialidades é tarefa da Geografia” (SANTOS, 2015, p.321), pois

[...] uma sociedade que constituiu suas relações por meio do racismo, [...][tem] em sua Geografia lugares e espaços com marcas dessa distinção social: no caso brasileiro, a população negra é francamente majoritária nos presídios e absolutamente minoritária nas universidades; [...] essas diferentes configurações espaciais se constituem em espaços de conformação das subjetividades de cada qual. Enfim, há toda uma série de sujeitos sociais cuja compressão da sua própria natureza sociológica implica considerar o espaço e a natureza - camponeses, os indígenas, os afrodescentes (com seus palenques, na Colômbia e na Venezuela, e seus quilombos no Brasil) os ecologistas, os moradores, os jovens-da-periferia (hip-hop), para não dizer do próprio operariado. (PORTO-GONÇALVES, 2002, p.4 apud SANTOS, 2007, p.29).

Depreendemos da citação acima que, se o racismo estruturou a sociedade brasileira, também organizou o espaço geográfico brasileiro. A população negra não ocupa qualquer espaço, pois “[...] a organização especializada das relações raciais constrói aquilo que Sansone chamou de 'espaços negros' e 'espaços brancos', na verdade, atribuições subjetivas de princípios valorativos a contextos e espaços" (SANTOS, 2015, p.328).

O espaço geográfico evidencia a acumulação desigual verificada através do tempo, possibilitando-nos análises a partir das relações raciais que configuraram esse espaço no passado e no presente. Assim, é possível observarmos as marcas espaciais da desigualdade racial no Brasil, produzidas pelo período escravocrata e pelos movimentos migratórios do pós-Abolição. A segregação racial se materializa nos surgimentos dos bairros, das periferias, das favelas espalhadas pelas cidades brasileiras, demarcando e expressando o lugar social e espacial da população negra.

[...] Os bairros e comunidades de maioria negra que temos hoje são, portanto, heranças do passado e também fruto do racismo no presente, que aparece como um regulador de acessos diferenciados a oportunidades sociais de renda, emprego, educação e também (consequentemente) moradia, grafando o espaço urbano como constituinte de um modelo capitalista periférico, dependente e baseado na hiperexploração da força de trabalho. (SANTOS, 2015, p.333). 
Além de marcar o espaço geográfico brasileiro, a raça estrutura a sociedade, interfere na cultura e na identidade enquanto nação, pois "[...] os estudos e as pesquisas sobre relações raciais, assim como a luta política do Movimento Negro, têm nos mostrado que, no contexto do racismo brasileiro, a 'raça' ganha mais destaque do que a língua ou a religião" (SILVEIRO, 2002, p.226 apud GOMES, 2011, p.98). Sendo assim, “[...] ]os processos de EJA e o campo das políticas públicas terão que se abrir para esse debate ao focalizarem a juventude e as pessoas adultas” (SILVEIRO, 2002, p.226 apud GOMES, 2011, p.98).

A Geografia pode desvelar as dimensões e desigualdades espaciais marcadas pela desigualdade social, mas também racial. Construindo análises comprometidas não só com a denúncia, mas com a luta pela igualdade de direitos, agregando às suas análises as condições sociais, econômicas e raciais dos sujeitos presentes nas salas de aula da EJA. Levando em conta não somente as ausências, mas ressignificando as lutas de resistência, a cultura, as marcas sociais e espaciais produzidas por essa população que vem ao longo dos séculos lutando pela igualdade de condições.

\section{REPRESENTAÇÃO DA POPULAÇÃO NEGRA NO MATERIAL DIDÁTICO DE GEOGRAFIA DO PROGRAMA "NOVA EJA": DESCONSTRUÇÕES DE ESTIGMAS E ESTEREÓTIPOS}

Para a construção do material didático do "Nova EJA", a Fundação CECIERJ selecionou tutores conteudistas que além de atuarem na Educação Básica, realizavam pesquisas a nível de Pós-Graduação, demonstrando a explícita tentativa de reunir teoriaprática-teoria. A disciplina Geografia ficou organizada da seguinte maneira:

Tabela: Distribuição dos tempos de Geografia pelos módulos do "Nova EJA"

\begin{tabular}{|c|c|c|}
\hline MÓDULOS & TEMPOS & VOLUMES \\
\hline I & 4 & $\mathbf{2}$ \\
\hline II & 0 & - \\
\hline III & 3 & 2 \\
\hline IV & 0 & - \\
\hline
\end{tabular}

Fonte: organizado pelo autor. 
Observamos que o novo modelo pedagógico adotado pelo SEEDUC para a EJA provocou forte fragmentação curricular, pois ao dividir nos módulos impares as ciências humanas, e nos pares, as ciências da natureza, impossibilita a realização de um trabalho integrado, que favoreça a compreensão, por parte dos discentes, das conexões presentes entre os componentes curriculares. 5

Entre os anos de 2013 e 2015, além do material distribuído semestralmente para os alunos, foram elaborados materiais didáticos impressos ${ }^{6}$ para uso exclusivo dos professores, contendo orientações didáticas e pedagógicas sobre os conteúdos. Foram disponibilizados também outros recursos didáticos, que por exigirem acesso à Internet, não puderam ser utilizados devido a falta de infraestrutura das unidades escolares. Tentando solucionar essa dificuldade, a SEEDUC disponibilizou nos encontros formativos CDs com o conteúdo, visando driblar os limites tecnológicos. De acordo com o manual do Programa "Nova EJA", cabe ao professor "repensar sua ação docente; estabelecer outro olhar sobre os limites e possibilidades dos alunos; exercitar um novo lócus enquanto mediador da construção do conhecimento e saberes" (2014, p. 16).

Podemos compreender que o docente possui o mero papel executor/mediador, ou seja, a sua função é, apenas, a de construir pontes ou facilitar a aprendizagem do educando/a. Ou seja, retira-se o lugar de intelectual, seu protagonismo em sala de aula (NICODEMOS e FLOR, 2019, p. 146, apud MONTEIRO, 2007), tanto na seleção dos conteúdos, como nas escolhas metodológicas e do material didático para a aula.

Concordo com Serra (2011) quando aponta para a importância que esse material didático tem para os docentes e discentes em suas atividades cotidianas, ou seja, eles não se configuram em material com formato igual aos livros didáticos que professores e alunos estão habituados a encontrar nas escolas. No entanto, assim como os livros didáticos convencionais, os materiais do Programa "Nova EJA" também são

\footnotetext{
5 Para maiores informações consultar a Matriz da (Nova) EJA Ensino Médio disponível no manual de orientações do Nova EJA, disponível no link: http://projetoseeduc.cecierj.edu.br/eja/manual-eja.pdf e

6 Módulo 1, volumes 1 e 2: http://projetoseeduc.cecierj.edu.br/eja/material-professor/modulo01/GEOGRAFIA-MODo1-VOLo1-02.pdf Módulo $\quad 3, \quad$ volume $\quad$ 1: http://projetoseeduc.cecierj.edu.br/eja/material-professor/modulo-o3/GEOGRAFIA-MODo3-

VOL01.pdf volume 2: http://projetoseeduc.cecierj.edu.br/eja/material-professor/modulo03/GEOGRAFIA-MODo3-VOL02.pdf
} 
considerados aqui como "uma versão didatizada do conhecimento para fins escolares e/ou com o propósito de formação de valores [...] incluindo as funções de referencial curricular, de instrumentalização de métodos de aprendizagem, ideológica e cultural e, mais restritamente, documental" (LOPES, 2007, p. 208).

Como um currículo escrito, isto é, um artefato cultural no qual se encontram concepções e discursos a serem veiculados como legítimos para a população escolar, tal material não pode ser considerado como decorrente apenas de discursos originados no âmbito do governo estadual, a serem disseminados verticalmente nas escolas de EJA. Concordando com Lopes (2007), em sua análise sobre os livros didáticos, os materiais do "Nova EJA" devem ser vistos como veiculadores de discursos recontextualizados da academia, das escolas e das disciplinas específicas para a modalidade EJA, revelando, assim, um processo muito mais complexo do que se poderia supor.

\begin{abstract}
O material didático não deve ser entendido somente como sendo uma seleção de conteúdos e atividades, pois ao mesmo tempo que ele permite controlar o processo de escolarização do público alvo, ele abre brechas mais autônomas em seu uso. Reconhecemos que o livro didático apresenta na sua estrutura uma intencionalidade na seleção dos conteúdos, nas indagações que são propostas para o professor e educando/a e nos textos que o compõem, porém o seu uso, dependem de um processo que foge do controle da burocracia educacional; as dinâmicas de aula que são geradas na mobilização de conteúdos/textos/temas de um livro didático são únicas e fortemente marcada pela ação ativa de professores e estudantes e ainda, pelo contexto onde está inserida a comunidade escolar. (NICODEMOS e FLOR, 2019, p. 149).
\end{abstract}

Ressalto que foram analisados os 4 volumes do material de Geografia, porém apresento as discussões somente dos volumes 1 e 2 do I módulo , pois os volumes 1 e 2 do III módulo 3 , apesar de trazerem conteúdos que poderiam discutir facilmente a questão racial no seu interior, não foram identificadas nenhuma imagem, dados ou assunto que fizessem alusão a população negra, o que aponta para um verdadeiro "apagão" das relações raciais durante um módulo inteiro.7

\footnotetext{
7 Volume 1: unidade 1 - A indústria e suas transformações socioeconômicas; unidade 2 - Sociedade em Redes, modelos, atores e lugares no mundo globalizado; unidade 3 - A questão energética no mundo contemporâneo. Volume 2: unidade 1 - Ambiente e dinâmica da paisagem: climas e biomas; unidade 2 - Dinâmica Ambiental: relevo e hidrografia; unidade 3 - Meio ambiente e sociedade.
} 
Quadro 1: Conteúdo de Geografia do I módulo, volume 1

\begin{tabular}{|c|c|c|}
\hline UNIDADES & TEMAS & SEÇÕ̃ES \\
\hline 1 & $\begin{array}{l}\text { Construção do espaço } \\
\text { geográfico - p.7 }\end{array}$ & $\begin{array}{l}\text { 1) O Espaço Geográfico - p.9 } \\
\text { 2) Paisagem - p.10 } \\
\text { 3) Território - p.13 } \\
\text { 4) Lugar - p.15 }\end{array}$ \\
\hline 2 & $\begin{array}{c}\text { Espaço e Fronteira - } \\
\text { p.25 }\end{array}$ & $\begin{array}{l}\text { 1) A importância das fronteiras e dos territórios - p.26 } \\
\text { 2) As fronteiras ontem e hoje - p.28 } \\
\text { 3) Os espaços de conflito - p.34 } \\
\text { 4) Espaço de solidariedade - p.47 }\end{array}$ \\
\hline 3 & $\begin{array}{l}\text { Regionalização } \\
\text { Fluminense: o Rio de } \\
\text { Janeiro em foco - p.61 }\end{array}$ & $\begin{array}{l}\text { 1) Conhecendo a regionalização brasileira e fluminense - } \\
\text { p.63 } \\
\text { 2) A influência do contexto histórico e socioeconômico } \\
\text { na configuracão regional - p.75 }\end{array}$ \\
\hline 4 & $\begin{array}{l}\text { Redescobrindo a } \\
\text { cartografia - p.99 }\end{array}$ & $\begin{array}{l}\text { 1) Um pouco mais de história ... - p.102 } \\
\text { 2) Elementos básicos para a compreensão dos mapas - } \\
\text { p.111 } \\
\text { 3) Identificando cartograficamente o estado do Rio de } \\
\text { Janeiro - p.13o } \\
\text { 4) Cartografia e as novas tecnologias - p.133 }\end{array}$ \\
\hline
\end{tabular}

Fonte: Nova Política de Educação de Jovens e Adultos. Ciências humanas e suas tecnologias: Geografia. Manual do Aluno. Módulo I. Volume I. Rio de Janeiro: Fundação CECIERJ, s/a.

Disponível em http://projetoseeduc.cecierj.edu.br/eja/material-aluno/moduloo1/Miolo_Ciencias_Humanas_Modo1_Volo1_Nova_eja_Aluno.pdf

No volume 1, pertencente ao I módulo, apesar de temas pertinentes às categorias analíticas da ciência geográfica, bem como a cartografia enquanto linguagem, os conteúdos relacionados à população negra não são abordados, nem mesmo como exemplificação da aplicabilidade de algum conceito. A ausência do tratamento dessas questões vai de encontro ao que Leomar Vazoller aponta:

[...] o estudo da Geografia pode debater, no interior de uma instituição escolar, uma infinidade de questões, entre elas, as raciais, a partir do objeto de estudo dessa disciplina, que é a produção do espaço, construído por diferentes povos, com todos os seus conflitos e tensões. (VAZOLLER, 2006, p.174).

Deste modo, observamos um material que não dialoga com a realidade da maioria dos alunos da EJA. O que se vê é uma geografia comprometida com a técnica, com o domínio da teoria descolada da realidade do estudante. Tal situação gera - para além de uma análise não completa do espaço geográfico onde os estudantes da EJA estão inseridos - uma geografia colonizada, desconsiderando a situação de mais da metade da população brasileira que, no último censo demográfico realizado pelo Instituto Brasileiro de Geografia e Estatística (IBGE), em 2010, tornou-se majoritária. 
Que identidade esses estudantes terão com esse material didático? Como eles farão a conexão com sua vida prática? Qual a representatividade que construirão? São questões que os agentes envolvidos com a educação, neste caso, a EJA, devem pensar e se questionar, para que tal situação não seja mais um dos fatores que proporcionam a evasão desses sujeitos já excluídos por diversas vezes do sistema escolar formal.

Somente na seção 3 (os espaços de conflito) - que está dentro da unidade 2 (Espaço e Fronteira) -, que aborda as principais disputais territoriais, é que teremos um conteúdo ligado à população negra. Entretanto, é uma abordagem feita de forma totalmente desequilibrada, visto que primeiro serão abordados os conflitos no território europeu, depois no continente asiático e, por fim, na África. Vale destacar que, em 13 páginas dedicadas ao assunto, o continente africano ocupa apenas a metade de uma página, sem mapas e ilustrações, apenas uma discussão superficial sobre os conflitos que lá ocorrem. Portanto, temos um desequilíbrio didático-pedagógico através de uma opção política de invisibilizar as relações intrínsecas que existem entre o continente africano e a sociedade brasileira.

Essa lacuna conteudista, essa ausência curricular sobre temas relacionados à população negra, impede os alunos de conhecerem sua própria condição humana, problematizá-la e ressignifica-la a partir dos conhecimentos técnico-científicos e filosóficos que a escola discute. Nesse sentido, os estereótipos e estigmas são reforçados, tendo um impacto negativo na vida dos estudantes pretos e pardos, e perpetuando, assim, o racismo escolar que se estende à sociedade como um todo.

Quadro 2: Conteúdo de Geografia do I módulo, volume 2

\begin{tabular}{|c|c|c|}
\hline UNIDADES & TEMAS & SEÇÕES \\
\hline 1 & $\begin{array}{l}\text { A distribuição desigual dos } \\
\text { indicadores da qualidade de } \\
\text { vida no espaço brasileiro e } \\
\text { mundial - p.7 }\end{array}$ & $\begin{array}{l}\text { 1) A população brasileira no Censo } 2010 \text { - p.9 } \\
\text { 2) Um Brasil de desigualdades - p.10 } \\
\text { 3) O Índice de Desenvolvimento Humano - IDH - p.11 } \\
\text { 4) Desigualdades: condições de vida no campo e na } \\
\text { cidade - p.18 }\end{array}$ \\
\hline 2 & $\begin{array}{l}\text { Dinâmica Populacional e } \\
\text { Mobilidade Humana: } \\
\text { motivos, causas e } \\
\text { consequências - p.27 }\end{array}$ & $\begin{array}{l}\text { 1) A Transição Demográfica e a Estrutura Etária de } \\
\text { uma População - p.29 } \\
\text { 2) Pessoas em movimento pelo mundo: a chamada } \\
\text { mobilidade humana - p.37 } \\
\text { 3) Mobilidade humana no Brasil - p.43 } \\
\text { 4) Causas e efeitos da mobilidade humana - p.48 }\end{array}$ \\
\hline 3 & $\begin{array}{l}\text { Cidade e qualidade de vida - } \\
\text { p.63 }\end{array}$ & $\begin{array}{l}\text { 1) O mundo cada vez mais urbano - p.67 } \\
\text { 2) As migrações para as cidades - p.77 } \\
\text { 3) O espaço urbano e suas desigualdades - p.82 }\end{array}$ \\
\hline
\end{tabular}




\begin{tabular}{|c|l|l|}
\hline & & 4) É possível pensar em uma cidade mais justa e \\
igualitária? - p.84
\end{tabular}

Fonte: http://projetoseeduc.cecierj.edu.br/eja/material-aluno/modulo-

01/Miolo_Ciencias_Humanas_Modo1_Volo2_Nova_eja_Aluno.pdf

Na abertura da unidade 1 do volume 2, que trata sobre a distribuição desigual dos indicadores da qualidade de vida no espaço brasileiro e mundial (para iniciar a discussão sobre o tema), há um trecho de reportagem sobre os dados do Censo demográfico de 2010, apresentando o resultado que demonstra a população negra como sendo majoritária no território brasileiro. Entretanto, a abordagem deixa a desejar: apenas é feita uma apresentação sem nenhuma problematização do assunto. Vejamos:

Figura 1: Trecho de reportagem que consta na página 8.

Veja alguns dos resultados publicados sobre o Censo 2010.

IBGE aponta aumento de brasileiros que se declaram pardos ou pretos

Soma de ambos os grupos representam 50,7\% de toda população; brancos não sảo mais maioria.

(Estado de S. Paulo, 22 de julho de 2011)

Fonte: http://projetoseeduc.cecierj.edu.br/eja/material-aluno/modulo01/Miolo_Ciencias_Humanas_Modo1_Volo2_Nova_eja_Aluno.pdf

Apenas apresentar essa informação, sem nenhuma discussão sobre o aumento da população negra na sociedade brasileira, é negligenciar toda uma história de luta e resistência que está por trás desses dados. Além disso, um dado estático, apenas numérico, retira a força do aluno de compreender as reais condições que os homens e as mulheres possuem em nossa sociedade. Logo, temos uma Geografia Tradicional que tem por premissa ser “apolítica”. Os avanços numéricos representam um aumento de autoafirmação da negritude, mas só isso não basta para empoderar a discussão em torno das relações raciais. 
O que nós, professores, podemos fazer para que, a partir do estudo da geografia, nossos alunos conheçam a condição humana dos negros, descubram seu próprio valor como agente ativo na sociedade e adquiram capacidade de analisar criticamente o tratamento desigual que é dispensado aos negros? Primeiramente, abordar esses aspectos não significa inventar novos conteúdos; propõe-se, antes, que ao discutir os conceitos e conteúdos oferecidos pela geografia, o professor rompa com abordagem tradicional dos temas a serem estudados. (VAZOLLER, 2006, p.175).

É no mínimo preocupante esta situação, uma vez que os materiais didáticos acabam sendo o guia dos conteúdos utilizados por inúmeros professores. Além disso, são os recursos didáticos que mais chegam aos discentes, portanto, é necessário estar explícito no material temas geográficos com discussões que tenham o recorte racial, para que não fique somente a critério da mediação do professor fazê-lo ou não.

\section{Figura 2: Imagem que ilustra o assunto sobre IDH na página 14.}

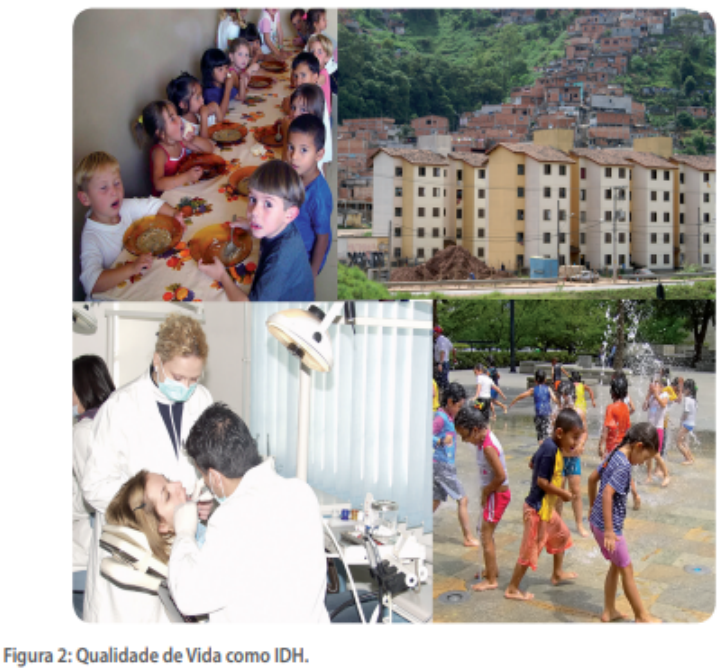

Fonte:http://projetoseeduc.cecierj.edu.br/eja/material-aluno/modulo01/Miolo_Ciencias_Humanas_Modo1_Volo2_Nova_eja_Aluno.pdf

Seguindo a discussão sobre a ausência de questões étnico-raciais no conteúdo de Geografia, na unidade 1, seção 3 (O Índice de Desenvolvimento Humano - IDH), também não se discutem as condições materiais de vida da população negra. Ademais, existe um apagamento da presença do homem negro, da mulher negra e das crianças negras, ao ilustrar uma temática que busca discutir diretamente os aspectos sociais da vida, mas traz somente uma imagem que, em relação as questões raciais, não quebra paradigmas, muito menos reconfigura a prática pedagógica em Geografia. 
Determinados conteúdos geográficos que constam nas diretrizes curriculares já possuem em si o recorte racial, como o estudo da população. "Entendemos que a geografia é a ciência da sociedade que busca decifrá-la à luz de suas realizações espacialmente definidas" (CARVALHO, 1994, p.81), porém, a partir da imagem acima (Figura 2), é possível questionar: em que lugar a população negra se encontra? Será que ela está tão à margem que sequer merece ser representada? Qual o impacto da ausência do recorte racial, situação que por inúmeras vezes repetida pode influenciar na autoestima dos discentes negros, em especial na EJA, onde são a maioria?

Outro problema encontrado no material analisado diz respeito à ilustração que retrata o negro de forma negativa (Figura 3). Quanto a isso, não é necessário negar que os fatores históricos colocaram a população negra em situação desigual socioeconomicamente. Sendo assim, em um material que representa o negro pelo viés da ausência ou precariedade, sem uma abordagem positiva, faz-se necessário que o professor discuta com seus alunos esses aspectos.

Figura 3: Exemplificação das condições de vida no campo e na cidade na página 19

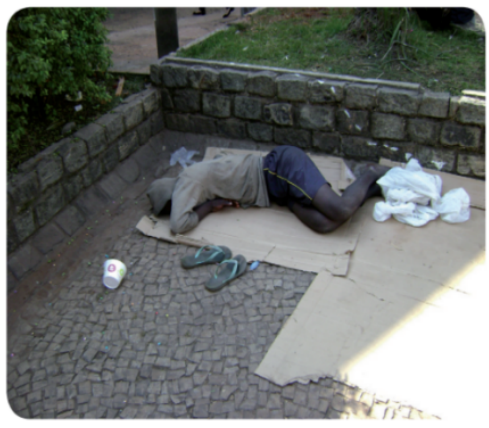

Morador de rua de Belo Horizonte

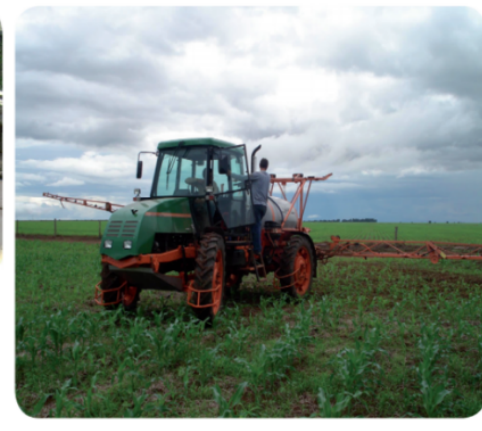

Fazenda em Jataí, Goiás

Fonte: http://projetoseeduc.cecierj.edu.br/eja/materialaluno/moduloo1/Miolo_Ciencias_Humanas_Modo1_Volo2_Nova_eja_Aluno.pdf

Ao apresentar no material a imagem de um negro, como morador em situação de rua, ao lado de um homem branco, associando-o a modernização do campo brasileiro, reforçando o preconceito e esteriótipo sobre a população negra. Essa situação é um problema político, didático e pedagógico, uma vez que a população negra, mesmo sendo a maioria em território brasileiro e ter contribuído em vários aspectos na construção desta nação, permanece à margem não só da sociedade, mas também de várias formas de representação. O problema principal não é a exposição da 
imagem acima no material didático, visto que a população negra é a maioria em relação à pobreza no Brasil, mas sim ser a única representação dessa parcela majoritária, sem o contraponto de um lugar positivo que lhe faça jus.

Outro aspecto analisado com resultado negativo sobre a abordagem do conteúdo da Geografia no material - embora não esteja relacionado diretamente à população negra brasileira, porém com conexões passiveis de serem feitas com o passado para se compreender o presente -, é a imagem do continente africano sem desenvolvimento, agrário e selvagem (Figura 4). Essa imagem ainda perdura, quando na verdade se quer, ao longo do volume, exemplifica a forma precarizada, e não moderna, de produzir alimentos agrícolas na África, em contraponto com uma cultura oriental representada por uma mulher, produzindo hortaliças orgânicas como uma nova forma de alimentação mais saudável e moderna. O que temos na imagem é uma cultura e forma de socialização presentes no continente africano expressas de maneira simplista, rupestre e homogênea, como se a única possibilidade de ser fosse aquela, negando, assim, toda a riqueza e diversidade cultural, econômica, política e geográfica desse continente.

Figura 4: Exemplificação de tipos de agriculturas nas páginas 110 e 112
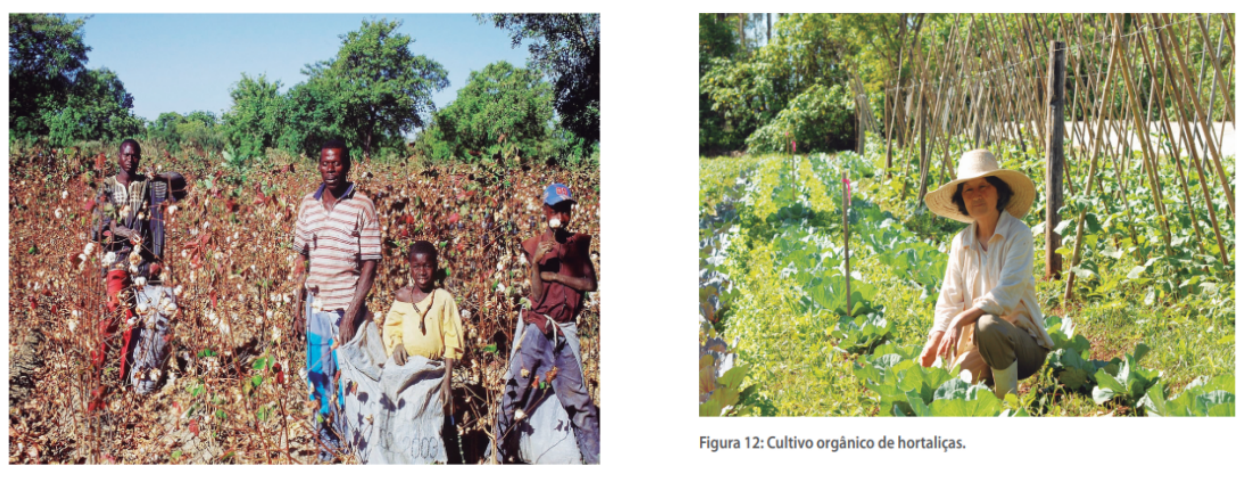

Figura 9: Plantation de algodāo.

Figura 12: Cultivo orgânico de hortaliças.

Fonte: http://projetoseeduc.cecierj.edu.br/eja/material-aluno/modulo01/Miolo_Ciencias_Humanas_Modo1_Volo2_Nova_eja_Aluno.pdf

Chaves (2006, p.24) salienta que “[...] é necessário melhorar o enfoque dado ao tema África na escola, uma vez que este se encontra diretamente ligado à história do 
povo afrodescendente no Brasil", pois isso é um ponto central para resgatar a autoestima, o respeito e os direitos básicos dos brasileiros que por muito tempo tiveram o acesso a eles negado.

\section{CONCLUSÕES}

Ao longo da história do Brasil, as diferenças têm colocado a população negra no não lugar, gerando desigualdade e exclusão, portanto, é preciso problematizar essa desigualdade no campo educacional, em especial na EJA. Discutir a África e a história dos africanos no Brasil, é reexistir, é resgatar uma diferença que gerou e gera exclusão até hoje. E a escola tem um papel central nisso, pois ela tem sido como instrumento principal na função reprodutora de uma cultura que prioriza valorizar e dar visibilidade a uma parte da sociedade em detrimento da outra. E a referida problematização passa por uma postura política, pois é inverter a lógica oficial já estabelecida e que teima em não ser questionada. É “enegrecer” a geografia, considerar que ao longo dos séculos a sociedade brasileira se estruturou a partir do racismo, e que cabe, antes de tudo, aos professores combaterem o racismo cotidianamente.

Compreender a questão racial e tudo aquilo que a ela está ligada, é discutir as relações de poder e dominação que permeiam tanto a vida fora da escola, quanto a cultura escolar. Sendo assim, os educadores e educadoras que atuam na EJA devem considerar que, a proposta de construção de uma pedagogia que valorize e respeite a identidade negra significa lidar com os conflitos, os confrontos, as contradições e as desigualdades, e isso se faz urgente e necessário. Especialmente na EJA, uma vez que é nessa modalidade de ensino que encontramos em maior número o segmento negro e pobre da população.

Assim, avançando para além de uma educação meramente tecnicista ou decodificadora de códigos linguísticos. A Geografia possibilita leituras de mundo para que os estudantes compreendam "a posição que Eva ocupa no seu contexto social8”,

$8 \quad$ http://www.epsjv.fiocruz.br/noticias/dicionario-jornalistico/pedagogia-dooprimido\#: :text=\%C3\%89\%20necess\%C3\%A1rio\%2ocompreender\%2oqual\%20a,Pedag\%C3\%B3gic as'\%2C\%2Ode\%2OMoacir\%2oGadotti\%2C 
para, a partir daí, construir análises críticas sobre as desigualdades econômicas e raciais que estruturam a sociedade brasileira. Ainda que isso não gere ações concretas de reivindicações sociais por parte dos estudantes, mas não terá sido uma educação despolitizada e alienante para a conformação.

Essas são questões importantes e passivas de análises no ensino de Geografia. São questionamentos pertinentes que cabe à Geografia colaborar na elaboração de respostas, principalmente em se tratando na EJA, que desde os primórdios da história da educação no Brasil, assim como a população negra, ficou renegada a segundo plano. Portanto, não é por acaso que a EJA tem classe e tem cor, é a classe dos destituídos economicamente, é raça da pele negra. São estudantes de trajetórias truncadas, que tiveram que "abrir mão” da escola, para trabalhar e, assim, sobreviver.

Então, amparados pela Lei 10.639/03, que torna obrigatório o ensino da História da África e dos afro-brasileiros, defendo que esse debate não fique somente circunscrito às disciplinas de História, Artes e Literatura, mas que se estenda aos componentes curriculares de outras disciplinas, como a Geografia, por exemplo. Partindo dessa defesa, foi preciso olhar para a relação entre a questão racial, a EJA e o ensino de Geografia tomando a produção acadêmica mais importante no cenário nacional.

Considerando que a Lei 10.639/03, fruto da luta dos Movimentos Negros no Brasil, completou 17 anos em janeiro de 2020. Vale ressaltar, que após uma década e meia, a referida lei ainda está desequilibrada nos sistemas educacionais, a balança entre as medidas de implementação e a execução na prática pedagógica em sala de aula, a condenam ao rol das leis em estados precários de implementação.

Isso se torna ainda mais grave quando analisamos a Educação de Jovens e Adultos Trabalhadores, já que um grande número dos educandos é negro, tal situação impede reflexões/problematizações das condições de vida dos negros e seus descendentes na sociedade brasileira, dificultando, portanto, a formação de uma força contra hegemônica ao mito da democracia racial e a não-exposição da desigualdade racial, algo tão necessário para a construção de uma sociedade racialmente equilibrada.

Com isso se tem uma enorme lacuna neste campo, logo a implementação da Lei 10.639/o3 precisa ser de fato efetivada pedagogicamente em todas as modalidades de 
ensino e disciplinas, para que alcançamos a desconstrução do mito da democracia racial e a construção de uma educação que, de fato, problematize as Relações Raciais na sociedade brasileira e a valorize a cultura afro-brasileira a fim de que ela fique em pé de igualdade com as demais matrizes culturais de formação da cultura brasileira.

As limitações ainda são muitas, apesar dos avanços conquistados. No entanto, aos poucos, é possível vencer o despreparo de professores, a desatenção das editoras pelo tema, a forma equivocada da abordagem sobre o continente africano pelos meios de comunicação e os descasos por muitos grupos na academia. Entretanto, para isso, é preciso reconstruir os cursos de licenciaturas, pois revisitando a minha formação inicial em Geografia, lembro-me bem da ausência de disciplinas sobre o continente africano e, também, sobre a EJA. Esta última é oferecida somente como eletiva pela faculdade de educação, ou seja, fica a critério do aluno ter, ou não, acesso à formação no campo.

Assim, medidas para uma distribuição mais justa do conhecimento são urgentes para que a educação brasileira não se aprisione ao mercado editorial, mas sim direcione a educação para formação de sujeitos capazes de refletirem criticamente sobre o seu papel na sociedade, buscando a equidade social e racial, bem como a quebra de preconceitos tacanhos e inconcebíveis. Vale ressaltar que o mercado editorial tem por premissa ser nacional e por essa razão nem sempre os conteúdos abordados dialogam de igual maneira com todos os estudantes do país. Entretanto, o material didático analisado foi produzido exclusivamente para alunos da EJA do estado do Rio de Janeiro e mesmo assim ele não consegue dialogar com esses alunos, uma vez que ele omite as questões raciais. O Brasil está tentando reescrever a sua história, construindo novos conceitos, olhares, perspectivas históricas e geográficas com o fim de corrigir distorções oriundas da cultura europeia que foi hegemônica ao longo de vários séculos em nossa sociedade.

Nesta perspectiva, a Geografia tem um papel importante, visto que ela instrumentaliza os estudantes a compreenderem a formação do espaço geográfico brasileiro e os povos que contribuíram para essa formação, dentre eles a população negra. Assim, reparar essa dívida social que a sociedade brasileira tem com essa população é necessária, urgente e uma questão de humanidade. É preciso valorizar o 
protagonismo negro invisibilizado ao longo do tempo e, portanto, potencializando criticamente o ser e estar dos estudantes jovens e adultos trabalhadores no mundo.

\section{Referencias}

ANDRADE, Rodrigo Coutinho. A Educação de Jovens e Adultos e o Programa Nova EJA: um olhar analítico sobre a categoria trabalho para formar trabalhadores. Revista Tamoios(online), v. 10, p. 35-56, 2014.

APPLE, Michael. Cultura e comércio do livro didático. In . Trabalho docente e textos: economia política das relações de classe e de gênero em educação. Porto Alegre: Artes Médicas, 1995, p. 81-105.

. Educação de Jovens e Adultos e questão racial: algumas reflexões iniciais.

In: ; SOARES, Leôncio; GIOVANETTI, Maria Amélia. (Org.). Diálogos na

Educação de Jovens e Adultos. Belo Horizonte: Autêntica, 2011. p. 87-104.

ARROYO, Miguel Gonzalez. A pedagogia multirracial popular e o sistema escolar. In: GOMES, Nilma Lino (Org.). Um olhar além das fronteiras: educação e relações raciais. Belo Horizonte: Autêntica, 2007. p. 111-130.

. Educação de Jovens e Adultos: um campo de direitos e responsabilidade pública. In: SOARES, Leôncio; GIOVANETTI, Maria Amélia; GOMES, Nilma Lino (Org.). Diálogos na Educação de Jovens e Adultos. Belo Horizonte: Autêntica, 2011. p. 19-50.

. Outros Sujeitos, Outras Pedagogias. Petrópolis, RJ: Vozes, 2012.

. Passageiros da noite: do trabalho para a EJA. Itinerários pelo direito a uma vida justa. Petrópolis, RJ: Vozes, 2017 [Edição digital].

CARVALHO, M. B. Artigo: A natureza na geografia do ensino médio. In: OLIVEIRA, A. U. (Org.). Para onde vai o ensino da geografia. São Paulo: Contexto, 1994.

CHAVES, Kelly dos Santos. A representação da África no livro didático de Geografia no ensino fundamental e médio. 2006. Monografia (Bacharelado em Geografia) IESA, Universidade Federal de Goiás Goiânia, 2006.

GOMES, Nilma Lino. Educação de Jovens e Adultos e questão racial: algumas reflexões iniciais. In: ; SOARES, Leôncio; GIOVANETTI, Maria Amélia. (Org.). Diálogos na Educação de Jovens e Adultos. Belo Horizonte: Autêntica, 2011. p. 87-104. 
GOVERNO DO ESTADO DO RIO DE JANEIRO. SECRETARIA DE ESTADO DE EDUCAÇÃO DO RIO DE JANEIRO. Bonificação por resultados: tudo que você precisa saber sobre bonificação por resultados da SEEDUC-RJ. 26 p. s/d (a).

HASENBALG, Carlos Alfredo. Discriminação e desigualdades raciais no Brasil.

Belo Horizonte, Editora UFMG; Rio de Janeiro: IUPERJ, 2005.

LIMA, Mônica. História da África: temas e questões para a sala de aula.In:

OLIVEIRA, Iolanda de e SISS, Ahyas (Org.). População Negra e Educação Escolar. Caderno Penesb 7. Niterói. Quartet/Eduff, 2006. p. 71-105.

PASSOS, Joana Célia dos. Juventude negra na EJA: os desafios de uma política pública. Tese (Doutorado em Educação). Centro de Ciências da Educação, Programa de Pós-Graduação em Educação, Universidade Federal de Santa Catarina, Florianópolis, 2010.

PONTUSCHKA, Nídia Nacib. A Geografia: ensino e pesquisa. In: CARLOS, Ana Fani Alessandri. (Org.). Novos Caminhos da Geografia. São Paulo: Contexto, 2005. p. 111-142.

.; PAGANELLI, Tomoko Iyda.; CACETE, Nuria Hanglei. Para ensinar e aprender Geografia. São Paulo: Cortez, 2007.

PORTO-GONÇALVES, Carlos Walter. A Geografia do social: uma contribuição para o debate metodológico para os estudos de conflitos e movimentos sociais na América Latina. Trabalho apresentado no Seminario Internacional "Conflitos social, militarizacións y democracia em América Latina - nuevos problemas y desafios para los estudios sobre conflictos y paz em la regións. Buenos aires: Clacso, 2002a

. A Geografia dos sistema mundo moderno-colonial numa perspectiva subalterna. IN: SANTOS, Renato Emerson. (Org.) Diversidade, Espaço e Relações Étnico-Raciais. O negro na Geografia do Brasil. Rio de Janeiro: Autêntica, 2007. p. 7-11.

SANTOS, Sales Augusto. A Lei 10.639/o3 como fruto da luta anti-racista do Movimento Negro. In: BRASIL. Ministério da Educação. Secretaria de Educação Continuada, Alfabetização e Diversidade. Educação antirracista: caminhos abertos pela Lei Federal n. 10.639/o3. Brasília, DF: MEC/SECADI, 2005. p. 21-38.

SANTOS, Renato Emerson dos. O ensino de Geografia do Brasil e as relações raciais: reflexões a partir da lei 10.639. In: . (Org.). Diversidade, espaço e relações étnico-raciais: O negro na Geografia do Brasil. Belo Horizonte: Autêntica, 2007. p. 21-42.

. O ensino de geografia e a Lei 10.639: algumas discussões de currículo. In: SACRAMENTO, Ana Cláudia Ramos; ANTUNES, Charlles da França; SANTANNA 
FILHO, Manoel Martins de. (Org.). Ensino de geografia: produção do espaço e processos formativos. Rio de Janeiro: Consequência/FAPERJ, 2015. p. 317-339.

SILVA, Natalino Neves da. Juventude Negra na EJA: o direito à diferença. Belo Horizonte: Mazza Edições, 2010.

VAZOLLER, Leomar dos Santos. As categorias Geográficas como fundamentos para os Estudos sobre a População Negra. In: OLIVEIRA, Iolanda de; SISS, Ahyas (Orgs.). População Negra e Educação Escolar. Caderno PENESB 7. Niterói: Quartet/Eduff, 2006b. p. 171-222

VENTURA, Jaqueline Pereira. A oferta de educação de jovens e adultos de nível médio no estado do Rio de Janeiro: primeiras aproximações. Revista Brasileira de Educação de Jovens e Adultos, vol. 4, n. 8, p. 9-35, 2016.

WETTSTEIN, Germán. O que se deveria ensinar hoje. In. OLIVEIRA, Ariovaldo Umbelino de. (Org.). Para onde vai o ensino de Geografia? São Paulo: Contexto, 2005. p. 125-134.

\section{Sobre o autor:}

\section{Tiago Dionísio da Silva}

Graduado em Geografia pela UFF. Mestre e Doutorando em Educação pela Universidade Federal Rural do Rio de Janeiro. Integrante do Grupo de Estudos e Pesquisas em Educação de Jovens e Adultos (GEPEJA/UFRRJ). Professor da Geografia da Secretaria de Estado de Educação do Rio de Janeiro (SEEDUC/RJ) desde 2009, mas atualmente trabalha na Coordenadoria de Articulação e Elaboração de Projetos Educacionais Inovadores (COAEP/SUPPES/SUBPAE/SEEDUC-RJ). E-mail: tiago_dionisio@hotmail.com.br 